\title{
Sandfly species diversity in association with human activities in the Kani tribe settlements of the Western Ghats, Thiruvananthapuram, Kerala, India
}

\author{
Srinivasan Ranganathan $/{ }^{+}$, Subramanian Swaminathan \\ Vector Control Research Centre, Indian Council of Medical Research, Pondicherry, Pondicherry, India
}

\begin{abstract}
Sandfly prevalence in the Kani tribe settlements of Western Ghats in India was investigated. A total of 1,279 sandflies comprising 17 species was obtained. Sandfly abundance showed a negative correlation $(r=-0.97, p=$ $0.003)$ with increase in altitudinal ranges from 0-1,000 $\mathrm{m}$. When sandfly samples were grouped according to landscape characteristics of the location, the estimated Shannon-Weiner index $(H)$ and species richness index (S) were high and species evenness index $(J)$ was low in settlements located at 0-300 m altitudinal range. On the contrary, the values of $H$ and $J$ were high, while $S$ was low at 301-600 $\mathrm{m}$ altitudinal range. With further increase in altitude, species diversity, $S$ and $J$ were low. Though the relative abundance of sandflies decreased with increase in altitude, the influence of altitudinal variation could not be attributed to determine sandfly diversity, since the number of sampling units were not uniform at all the altitudinal gradients due to nonavailability of suitable resting shelters. Sandfly species showed great aggregation at 0-300 m altitude interval, where not only the number of settlements were maximum $(n=19)$, but also the environmental conditions favoured sandfly abundance due to the concentration of tribal settlements, human dwellings and his activities.
\end{abstract}

Key words: sandfly diversity - human activity - tribal settlements - the Western Ghats - Kerala - India

Environmental conditions were conducive for the occurrence of diseases transmitted by haematophagous arthropods. Malaria, leishmaniases and viral encephalitis diseases propagated by blood sucking insects cause several millions of deaths among human in countries located in the tropical region (Jacobson et al. 2003). Leishmaniasis is an example of the diseases caused by flagellate parasites of the genus Leishmania and transmitted by female sandflies (Diptera: Psychodidae) (Killick-Kendrick 1990). These insects are adapted to a range of environments and conditions, with some species having wide geographical distribution, consequently occupying various biomes (Lewis 1978, 1987, Dhanda et al. 1983, Killick-Kendrick 1983, Kalra \& Bang 1988, Kumar et al. 1992, Srinivasan et al. 2013). The Indian subcontinent, which has diversified physiographic conditions, has many foci of visceral and cutaneous leishmaniasis due to sandfly abundance.

Distribution of sandflies in relation to ecological factors and altitude has been studied by several investigators in India. Ranjan et al. (2005) reported that soil, water table, temperature, annual rainfall, humidity and vegetation favour sandfly distribution. Bhunia et al. (2010) made an in-depth investigation and stated that in kala-azar endemic areas of Bihar in India the number of kala-azar

doi: 10.1590/0074-02760140272

Financial support: ICMR

+ Corresponding author: r.s_vasan@yahoo.com

Received 30 July 2014

Accepted 25 February 2015 cases decreased with increase in altitude ( $>50$ and 300 $\mathrm{m}$ ) and beyond the altitude $300 \mathrm{~m}$ no kala-azar case was recorded, which implies that topography play a major role in determining sandfly distribution. Landform and land usage pattern have been reported to influence sandfly abundance in coastal areas of Pondicherry (Srinivasan et al. 2013). Recently, cutaneous leishmaniasis cases have been reported among the Kani tribe community, which is one of the Indian ethnicity or social groups settled in southernmost part of the Western Ghats, district of Thiruvananthapuram, state of Kerala (Simi et al. 2010, VCRC 2012). Srinivasan et al. (2014) described a new sandflies species from this region of the Western Ghats. As the area is known for cutaneous leishmaniasis transmission, a cross-sectional study was conducted to determine sandfly species composition and their abundance in relation to human activity in the tribal settlements.

\section{MATERIALS AND METHODS}

The Western Ghats is a mountain range with reserve forests with an immense importance with unique biophysical and ecological feature. Scrub vegetation, deciduous vegetation, semi-ever green and ever green forests were found in the Western Ghats. At very high altitude grasslands occupied the hill top (Parthasarathy 1999, Sabu et al. 2008). Existence of the Western Ghats on the eastern side of Kerala in India has created a barrier across the path of the southwest monsoon. This had resulted in the creation of a significant climatic variation with abundant rainfall on the windward side and a dry belt on the lee eastern side. Temperature was relatively high during March-May and again in September. During that period temperature reached to a maximum of $33^{\circ} \mathrm{C}$ which was considered less when compared with other states of In- 
TABLE I

Study area: details of latitude, longitude, altitude and altitudinal ranges (m) of the Kani tribe settlements

\begin{tabular}{|c|c|c|c|c|c|}
\hline $\begin{array}{l}\text { Settlement } \\
\text { number }\end{array}$ & Settlements & $\begin{array}{l}\text { North } \\
\text { latitude }\end{array}$ & $\begin{array}{c}\text { East } \\
\text { longitude }\end{array}$ & $\begin{array}{l}\text { Altitude } \\
(\mathrm{m})\end{array}$ & $\begin{array}{l}\text { Altitudinal } \\
\text { range }\end{array}$ \\
\hline 1 & Kombidi & $08^{\circ} 35^{\prime} 14.7 ”$ & $077^{\circ} 07^{\prime} 40.1^{\prime \prime}$ & 72 & $0-300$ \\
\hline 2 & Podium & $08^{\circ} 34^{\prime} 55.5^{\prime \prime}$ & $077^{\circ} 07^{\prime} 27.3^{\prime \prime}$ & 110 & $0-300$ \\
\hline 3 & Kamalagam & $08^{\circ} 34^{\prime} 55.5^{\prime \prime}$ & $077^{\circ} 07^{\prime} 27.3^{\prime \prime}$ & 110 & $0-300$ \\
\hline 4 & Mela Amala & $08^{\circ} 34^{\prime} 55.5^{\prime \prime}$ & $077^{\circ} 07^{\prime} 27.3 "$ & 110 & $0-300$ \\
\hline 5 & Patanipara & 08³5'29.7” & $077^{\circ} 09^{\prime} 30.6 "$ & 119 & $0-300$ \\
\hline 6 & Chonambara & $08^{\circ} 35^{\prime} 39.3 ”$ & 07709’09.9" & 126 & $0-300$ \\
\hline 7 & Kaithode & $08^{\circ} 35^{\prime} 11.7 ”$ & $077^{\circ} 07^{\prime} 50.7^{\prime \prime}$ & 148 & $0-300$ \\
\hline 8 & Mangode & 08³5'11.7” & $077^{\circ} 07^{\prime} 50.7^{\prime \prime}$ & 148 & $0-300$ \\
\hline 9 & Valpara & $08^{\circ} 35^{\prime} 16.3^{\prime \prime}$ & $077^{\circ} 10^{\prime} 15.2^{\prime \prime}$ & 173 & $0-300$ \\
\hline 10 & Ariyavila & $08^{\circ} 35^{\prime} 08.5^{\prime \prime}$ & $077^{\circ} 09^{\prime} 58.5^{\prime \prime}$ & 174 & $0-300$ \\
\hline 11 & Molamode & $08^{\circ} 36 ’ 36.1 ”$ & 077¹0’18.7”' & 190 & $0-300$ \\
\hline 12 & Erambiade & $08^{\circ} 36^{\prime} 43.9^{\prime \prime}$ & $077^{\circ} 11^{\prime} 22.5^{\prime \prime}$ & 194 & $0-300$ \\
\hline 13 & Monumukkam & $08^{\circ} 35^{\prime} 56.8^{\prime \prime}$ & 07709’13.6" & 197 & $0-300$ \\
\hline 14 & Ploth & $08^{\circ} 35^{\prime} 56.8^{\prime \prime}$ & 07709’13.6" & 197 & $0-300$ \\
\hline 15 & Panacavu & $08^{\circ} 35^{\prime} 56.8^{\prime \prime}$ & 07709’13.6" & 197 & $0-300$ \\
\hline 16 & Keezheamala & $08^{\circ} 35^{\prime} 18.5^{\prime \prime}$ & $077^{\circ} 09^{\prime} 40.9^{\prime \prime}$ & 204 & $0-300$ \\
\hline 17 & Ayiramkal & $08^{\circ} 33^{\prime} 48.3^{\prime \prime}$ & $077^{\circ} 11^{\prime} 49.7^{\prime \prime}$ & 217 & $0-300$ \\
\hline 18 & Mukothivayal & 08³3’48.3” & $077^{\circ} 11^{\prime} 49.7^{\prime \prime}$ & 217 & $0-300$ \\
\hline 19 & Amode & $08^{\circ} 33^{\prime} 10.8^{\prime \prime}$ & $077^{\circ} 12^{\prime} 07.2^{\prime \prime}$ & 223 & $0-300$ \\
\hline 20 & Pothode & $08^{\circ} 36^{\prime} 26.1 ”$ & $077^{\circ} 11^{\prime} 36.3 ”$ & 369 & $301-600$ \\
\hline 21 & Cherumangal & 08³6’26.1” & $077^{\circ} 11 ’ 36.3 ”$ & 369 & $301-600$ \\
\hline 22 & Viavila & $08^{\circ} 36^{\prime} 26.1 ”$ & $077^{\circ} 11 ’ 36.3 ”$ & 369 & $301-600$ \\
\hline 23 & Anakkal & $08^{\circ} 36^{\prime} 26.1 ”$ & $077^{\circ} 11^{\prime} 36.3^{\prime \prime}$ & 369 & $301-600$ \\
\hline 24 & Pattampara & $08^{\circ} 36^{\prime} 26.1 ”$ & $077^{\circ} 11^{\prime} 36.3^{\prime \prime}$ & 369 & $301-600$ \\
\hline 25 & Kunnadi & $08^{\circ} 36^{\prime} 26.1 ”$ & $077^{\circ} 11^{\prime} 36.3 ”$ & 369 & $301-600$ \\
\hline 26 & Thannipara & $08^{\circ} 34^{\prime} 56.6^{\prime \prime}$ & $077^{\circ} 12^{\prime} 04.1 ”$ & 439 & $301-600$ \\
\hline 27 & Kunnatheri & $08^{\circ} 35^{\prime} 50.2^{\prime \prime}$ & $077^{\circ} 11^{\prime} 50.4^{\prime \prime}$ & 739 & $601-800$ \\
\hline 28 & Thottinpura & $08^{\circ} 36^{\prime} 16.3 ”$ & $077^{\circ} 11^{\prime} 58.4^{\prime \prime}$ & 820 & $801-1,000$ \\
\hline 29 & Baren land & $08^{\circ} 36^{\prime} 18.3^{\prime \prime}$ & $077^{\circ} 11^{\prime} 94.4 "$ & 1,001 & 1,000 \\
\hline
\end{tabular}

dia. The minimum temperature remained within $20^{\circ} \mathrm{C}$. Summer was followed by southwest monsoon that started pouring in June and continued till September. The northeast monsoon began in October and stopped at the end of December. Peak rain occurred in October. With the arrival of winter, there was a drop in the temperature. The winter lasted from November-January or February. There were great varieties of vegetation all along the Western Ghats: scrub jungles, dry and moist deciduous forests and semievergreen, evergreen forests and grassland (Parthasarathy 1999). Explorations conducted by the Kerala Forest Research Institute, Zoological Survey of India and other institutions brought out the wealth of the fauna and emphasised the need for further studies (Lewis 2012). The diversity of insect fauna of this region remained practically unknown, till the area came into the attention with the proposal of a hydel project (Gadgil 2012).

The Kani tribes were one of the Indian ethnicity or social groups who were settled in 28 settlements over southernmost part of the Western Ghats $\left(08^{\circ} 37^{\prime} 49.7^{\prime \prime} \mathrm{N}\right.$ $077^{\circ} 11^{\prime} 29.7^{\prime \prime} \mathrm{E}, 08^{\circ} 36^{\prime} 51.2^{\prime \prime} \mathrm{N} 077^{\circ} 09^{\prime} 54.9^{\prime \prime} \mathrm{E}$, with alti- tude ranging from $0-1,000 \mathrm{~m}$ ). The tribes were inhabiting in hut dwellings made of thatched roof (dry leaves, polythene sheets, tin sheets), walls with either dry plant materials, bamboo slots, sticks or polythene sheets, and a floor with mud or mud floor, each with one-two rooms (76.2\%). The remaining tribes occupied in houses made of brick wall plastered with cement and rein-forced concrete cement roof (23.8\%). Their traditional occupation included collection of nontimber forest products such as honey, bee-wax, medicinal plants, gums etc. All the tribal settlements were located in the difficult-to-reach area (VCRC 2012) and were under the control of Kuttichal Primary Health Care area, Nedumangadu, Thiruvananthapuram.

A cross sectional survey of sandflies was made in all the 28 tribal settlements, between November 2011-March 2012, which were conducive for sandfly survival due to optimum temperature and relative humidity (RH). Handheld mechanical aspirator collections were made indoors (human dwellings and cattle-sheds) and outdoors (tree holes, tree-buttresses, rock holes, rodent burrows) for collecting sandflies found on natural resting shelters. For 
this purpose, in each settlement, 10 samplings units, five number each, indoor and outdoor, were chosen based on random sampling method and sandflies were collected spending $10 \mathrm{~min}$ in each sampling unit, between 10:00 am 12:00 am. Light traps (each 5 number indoor and outdoor) were installed and activated between 05:00 pm-10:00 am using 12 watt batteries. Sticky traps (each 5 indoor and outdoor) made of white cardboard sheets $(30 \times 21 \mathrm{~cm})$ and smeared with castor oil were placed indoors and outdoors at suspected breeding places of sandflies. Due to wild animal threat handheld aspirator collections were made after 10:00 am in the tribal settlements. Sandflies obtained in all collection methods were identified to species referring the standard keys (Artemiev 1978, Lewis 1978, Kalra \& Bang 1988). The geographic coordinates were measured $\sim$ middle of each settlement, employing handheld Garmin GPS map 76 (Table I).

The density of sandflies was calculated for each type of collection methods. Sandflies obtained using handheld aspirator were divided by the total number of man-hour (MHR) spent for collection and the density was expressed in number of sandflies per MHR. Similarly, the number of sandflies obtained from light trap and sticky trap collections were divided by the total number of traps used and the density was mentioned number of sandflies/light trap and number of sandflies/sticky trap, respectively.

Since the number of settlements was not uniform at each altitude to assess sandfly species diversity in relation to altitude, the elevation gradients of the Western Ghats of the tribal settlements were grouped into four categories: category I, 0-300 m with scrub vegetation, category II, 301-600 $\mathrm{m}$ with deciduous vegetation, category III, $601-800 \mathrm{~m}$ with semi-ever green, and category IV, 801-1,000 m with ever green forest. Data on soil type, canopy coverage and slope of the terrain published by Sabu et al. (2008) and Pascal et al. (2004) for the Western Ghats region were taken into consideration for analysis.

Sandfly species diversity in relation to altitude was evaluated. Shannon-Weiner index $(\mathrm{H})$ and evenness in-

\section{TABLE II}

Total number of sandflies obtained from different types of collections made in the Kani tribe settlements located at different altitudes

\begin{tabular}{lcccc}
\hline $\begin{array}{l}\text { Type of } \\
\text { collection }\end{array}$ & Habitat & $\begin{array}{c}\text { Male } \\
(\mathrm{n})\end{array}$ & $\begin{array}{c}\text { Female } \\
(\mathrm{n})\end{array}$ & $\begin{array}{c}\text { Total } \\
\mathrm{n}(\%)\end{array}$ \\
\hline Light trap & Cattle shed & 45 & 7 & $52(4.1)$ \\
& Human dwelling & 9 & 5 & $14(1.1)$ \\
\multirow{3}{*}{ Resting } & Outdoor & 0 & 1 & $1(0.1)$ \\
& Cattle shed & 72 & 1 & $73(5.7)$ \\
& Human dwelling & 292 & 708 & $1,000(78.2)$ \\
Sticky trap & Outdoor & 51 & 69 & $120(9.4)$ \\
& Indoor & 5 & 3 & $8(0.6)$ \\
& Human dwelling & 0 & 0 & $0(0)$ \\
& Outdoor & 6 & 5 & $11(0.9)$
\end{tabular}

dex $(J)$ were computed from the data obtained from different types of collections of sandflies in all the 28 tribal settlements, as follows: $\mathrm{H}=\Sigma \mathrm{Pi} \log \mathrm{Pi}$, where $\mathrm{Pi}$ is the proportion of total samples belonging to $\mathrm{i}$-th species, $\mathrm{J}$ $=\mathrm{H} / \mathrm{ln}(\mathrm{S})$, where $\mathrm{S}$ is the species richness, equal to the number of species in the total samples. The statistical analysis was performed in PAST (Hammer et al. 2001).

Even though sandfly diversity depends on $\mathrm{S}$, to know whether sandflies in these tribal settlements were distributed evenly, a regression analysis was also made using $\mathrm{H}$ and $\mathrm{S}$.

\section{RESULTS}

A total of 1,279 sandflies was obtained from all the 28 settlements. Among the three collection methods, handheld aspirator collection yielded significantly $(\mathrm{p}<0.05)$ more number of sandfly specimens $(93.3 \%)$ followed by light trap (5.3\%) and sticky trap catches (1.4\%) (Table II). Seventeen species of sandflies $(\mathrm{n}=1,279)$ were recorded: Phlebotomus (Euphlebotomus) argentipes (25.7\%), Phlebotomus (Anaphlebotomus) colabaensis (2.9\%), Phlebotomus (Anaphlebotomus) stantoni (1.6\%), Sergentomyia (Parrotomyia) baghdadis $(50.7 \%)$, Sergentomyia (Parrotomyia) babu (5.6\%), Sergentomyia (Neophlebotomus) zeylanica (4.9\%), Sergentomyia (Neophlebotomus) arboris (1.7\%), Sergentomyia (Parrotomyia) kauli (1.6\%), Sergentomyia (Neophlebotomus) monticola (1.2\%), Sergentomyia (Parrotomyia) barraudi $(0.9 \%)$, Sergentomyia (Parrotomyia) jerighatiansis $(0.9 \%)$ Sergentomyia (Neophlebotomus) malabarica (0.6\%), Sergentomyia (Parrotomyia) rectangulata (0.5\%), Sergentomyia (nic nic gr.) bailyi (0.5\%), Sergentomyia (Parrotomyia) shorttii $(0.3 \%)$, Sergentomyia (Neophlebotomus) dhandai $(0.2 \%)$ and Sergentomyia (Sintonius) hospitii (0.2\%). P. (Eup.) argentipes, the proven vector of visceral leishmaniasis (kala-azar) in India, was found prevalent in 21 out of 28 settlements. All the 17 species were recorded indoors, among them, only 11 from outdoors.

There were variations in the number of settlements at each altitudinal range. The number of settlements found

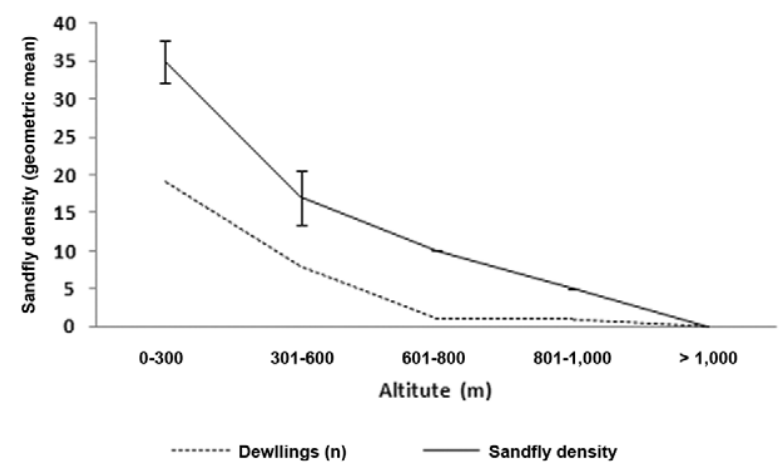

Fig. 1: sandfly abundance in relation to altitude (m) and number of sandfly sampling units. 
TABLE III

Density (mean \pm standard deviation) of female sandflies obtained from different types of collections in Kani tribe settlements located at different altitudinal ranges

\begin{tabular}{|c|c|c|c|c|c|c|}
\hline \multirow{2}{*}{$\begin{array}{l}\text { Altitudinal } \\
\text { ranges }\end{array}$} & \multicolumn{2}{|c|}{$\begin{array}{c}\text { Hand-held aspirator } \\
\text { (female number/man-hour) }\end{array}$} & \multicolumn{2}{|c|}{$\begin{array}{c}\text { Light traps } \\
\text { (female number/light trap/night) }\end{array}$} & \multicolumn{2}{|c|}{$\begin{array}{c}\text { Sticky trap } \\
\text { (female number/sticky trap) }\end{array}$} \\
\hline & Indoor & Outdoor & Indoor & Outdoor & Indoor & Outdoor \\
\hline $0-300 \mathrm{~m}$ & $9.6 \pm 8.6$ & $1.2 \pm 1.0$ & $0.32 \pm 0.2$ & $0.72 \pm 0.2$ & $0.09 \pm 0.1$ & $0.32 \pm 29$ \\
\hline $301-600 \mathrm{~m}$ & $6.4 \pm 9.0$ & $0.9 \pm 0.81$ & $0.2 \pm 0.91$ & $0.2 \pm 0.8$ & $0.13 \pm 0.1$ & $0.15 \pm 0.1$ \\
\hline $601-800 \mathrm{~m}$ & 1.0 & 0.7 & 0.4 & 0.4 & 0 & 0.2 \\
\hline $801-1,000 \mathrm{~m}$ & 0.7 & 0.2 & 0 & 0 & 0 & 0.19 \\
\hline$>1,000 \mathrm{~m}$ & Nil & Nil & Nil & Nil & Nil & Nil \\
\hline
\end{tabular}

at altitudinal ranges between 0-300 $\mathrm{m}, 301-600 \mathrm{~m}$ and 601-800 m, were 19, eight and one in number, respectively. At altitudinal ranges between $801-1,000 \mathrm{~m}$ and $>1,000$ $\mathrm{m}$, no settlement was found. A highest frequency of sandflies $(n=998)$ was captured in the settlements located at altitude ranging between $0-300 \mathrm{~m}$, representing thrice the total captured specimens compared to those obtained in settlements located at altitudinal ranges between 301-600 $\mathrm{m}(\mathrm{n}=275), 601-800 \mathrm{~m}(\mathrm{n}=10)$ and 801-1,000 $\mathrm{m}(\mathrm{n}=5)$ (Fig. 1). No sandfly was obtained at $>1,000 \mathrm{~m}$ elevation. Of the 17 species recorded, 14 species were found up to an altitudinal range of $800 \mathrm{~m}$, while $S$. (Par.) baghdadis and $S$. (Par.) babu were found up to $1,000 \mathrm{~m}$ altitude.

Density of sandflies obtained indoor and outdoor using handheld mechanical aspirator, light trap and sticky traps in settlements located at all altitudinal ranges were given in Table III. Although the number of sandflies collected was divided by the total MHR spent, mean density of sandflies obtained from settlements located at altitudinal ranges between 0-300 $\mathrm{m}$ was the highest. The increase in altitudinal ranges showed a decrease in sandfly density. Handheld aspirator collection yielded significantly high $(\mathrm{p}<0.05)$ sandfly density than that of the light trap and sticky trap collections.

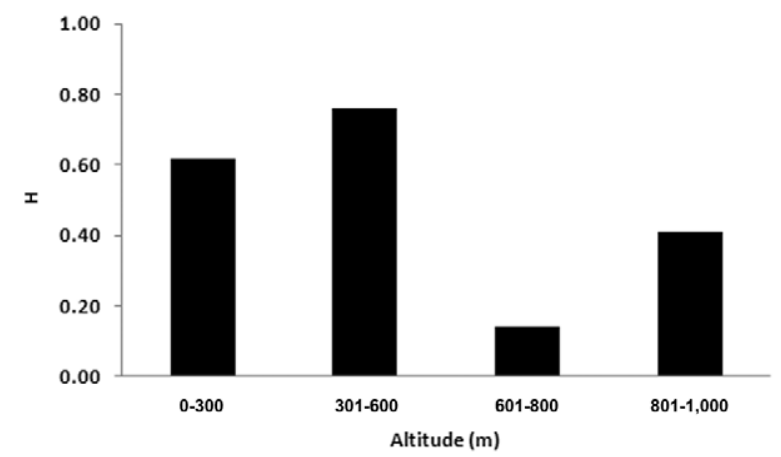

Fig. 2: sandfly species Shannon-Weiner index $(\mathrm{H})$ in relation to increase in altitude in southernmost part of the Western Ghats.
The sandfly species diversity as indicated by the value of $\mathrm{H}, \mathrm{J}$ and $\mathrm{S}$ among the settlements located at various altitudinal gradients (Figs 2-4) showed significant differences $(r=-0.97, p=0.003)$. In settlements located at the altitudinal range between 0-300 $\mathrm{m}$, both species diversity and $\mathrm{J}$ were relatively low and $\mathrm{S}$ was high. On the other hand, species diversity and J were high and $\mathrm{S}$ was low at altitudinal range $301-600 \mathrm{~m}$. With further increase in altitude $(>601 \mathrm{~m})$ species diversity, $\mathrm{J}$ and $\mathrm{S}$ were very low.

Although the relative abundance of sandflies showed a negative correlation $(r=-0.97, p=0.003)$ with increase in altitudinal ranges, altitudinal variations alone could not be attributed to determine sandfly diversity in the study, since the numbers of sandfly sampling units were not uniform at all the altitudinal gradients. The number of tribal settlements and number of human dwellings decreased with increase in altitude $(r=-0.82, p=0.001)$ due to lack of transport and communication, as the mountain region was difficult-to-reach. Human dwellings were found scattered in 19 settlements at the lower altitudinal gradient (0-300 $\mathrm{m})$. S was high in the settlements located at lower altitudinal range. The reduction in $\mathrm{H}$ and $\mathrm{J}$ was due to irregular distribution of sandflies in the altitudinal range between 0-300 m (Fig. 5) where a particular sandfly species, i.e., Se. (Par.) bagdhadis dominated the sandfly community.

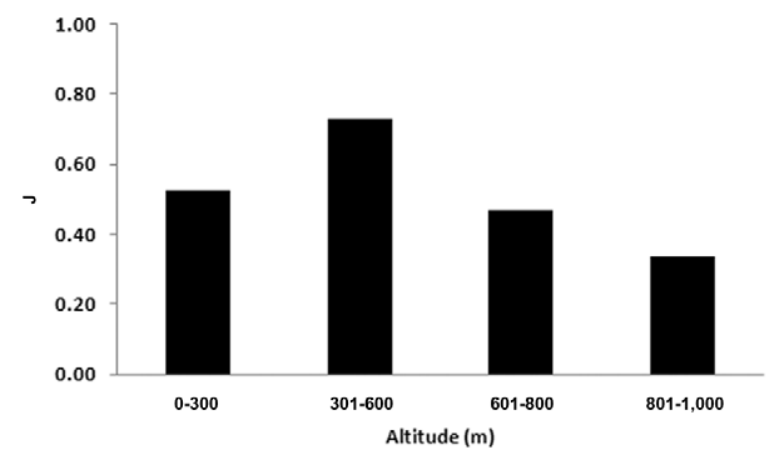

Fig. 3: sandfly species evenness index $(\mathrm{J})$ in relation to increase in altitude in southernmost part of the Western Ghats. 


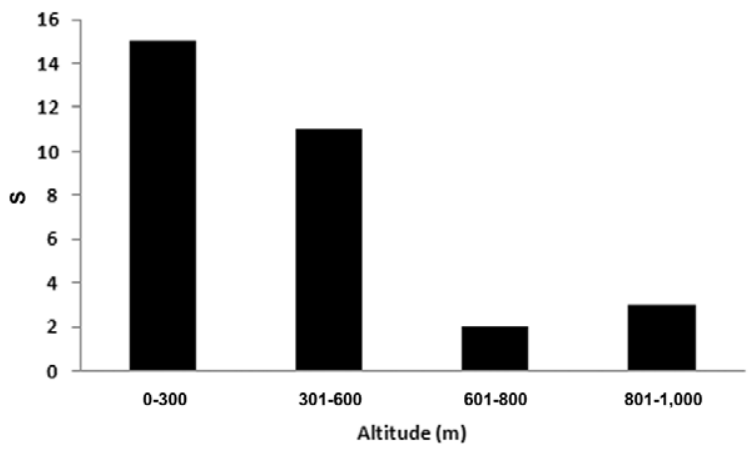

Fig. 4: sandfly species richness index $(S)$ in relation to increase in altitude in southernmost part of the Western Ghats.

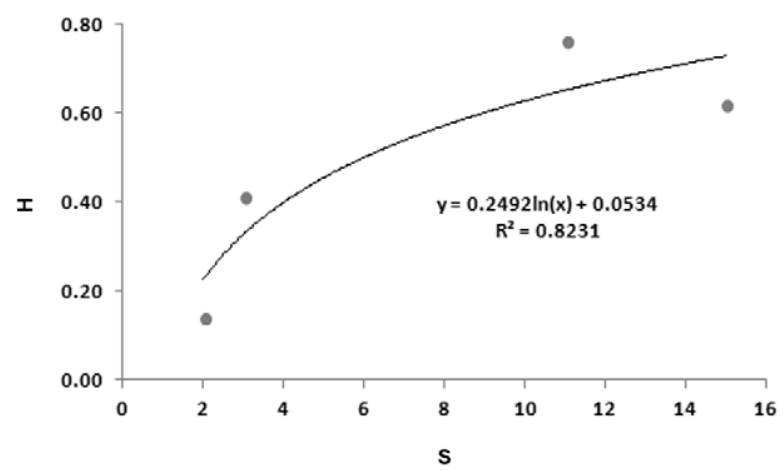

Fig. 5: relationship between Shannon-Weiner index (H) and species richness index (S) in ecosystem disturbed by human activity is shown in logarithmic regression equation.

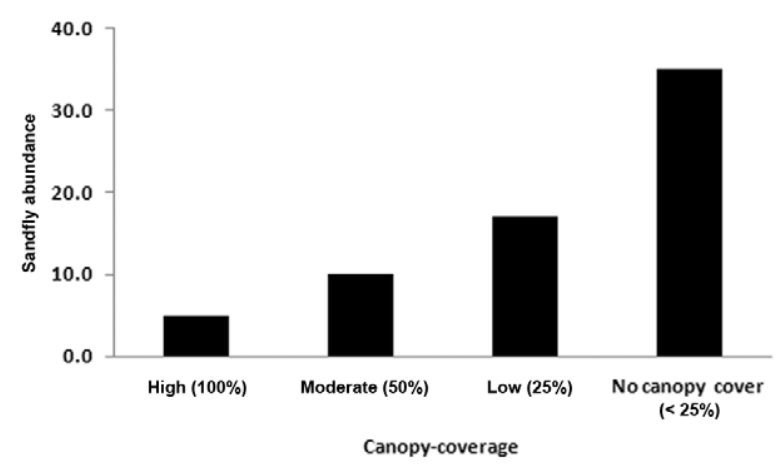

Fig. 6: sandfly abundance in relation to canopy-coverage in southernmost part of the Western Ghats.

When the influence of soil type was analysed, sandflies were found to be abundant in settlements having humiferous soil [geometric mean $(\mathrm{GM})=35.0$ ] followed by sandy soil $(\mathrm{GM}=16)$ and red soil $(\mathrm{GM}=5)$. Sandfly abundance showed a negative association with increase in mountain slope $\left(Y=-9.6651 x-7.8912 ; R^{2}=0.9712\right)$. Forest canopy- coverage also influenced sandfly abundance to a greater extent (Fig. 6). Increase in canopy-coverage decreased sandfly abundance $\left(\mathrm{Y}=9.7074 \mathrm{x}-7.5174 ; \mathrm{R}^{2}=0.9096\right)$ in the tribal settlements. Sandflies were found to be significantly abundant $\left(\chi^{2}=9891.5 ; \mathrm{p}=0.0001\right)(\mathrm{n}=998)$ in settlements located at altitude, ranging between 0-300 m, where the number of tribal settlements was also high ( $\mathrm{n}=$ 19) compared to those located at higher altitudinal ranges $(301-1,000 \mathrm{~m})$. Therefore, the increase in the number of tribal settlements has influenced of environment due to human activities resulting in sandfly abundance.

\section{DISCUSSION}

The Western Ghats is one of the biodiversity hot spots in the world. This mountain range mediates with the rainfall pattern in India by intercepting the southwestern monsoon winds and experiences heavy annual rainfall during the southwest monsoon from June-September and northeast monsoon from October-December. The wide variation in rainfall patterns coupled with the complex geography, particularly the altitude, produces a great variety of vegetation types (Parthasarathy 1999). Although forest vegetations, humiferous soil with leaf litter, ambient temperature, RH and heavy rain fall create ecological richness and provides conditions conducive for sandfly propagation and survival in this region, the number of sandflies caught in domestic and peridomestic habitats decreased with increase in altitudinal ranges. The capture of sandflies within the disturbed forest area located at 0-300 $\mathrm{m}$ altitudinal range was higher than the captures made at the areas located at 301-600 $\mathrm{m}$ and $>600 \mathrm{~m}$ altitudinal range.

As the mountain range is difficult-to-reach, the number of human settlements decreased with increase in altitude. Hence, most of the human settlements were located at lower altitudinal ranges. Therefore, human activities were confined to areas located at altitudes, ranging between 0-300 $\mathrm{m}$. The environment was influenced with human activities for cultivation, which created new habitats, food sources and accumulation of organic materials, resulting in sandfly abundance. Besides, moisture content of the humiferous soil also increased due to irrigation, supporting sandfly breeding. Srinivasan et al. (2013) also authenticated the present finding. They have reported that fluvial land form supporting cultivation and luxuriant vegetation, favoured sandfly abundance and diversity in rural areas in southern India. However, the region located at higher elevations where the environment remained unaltered due to no or lesser human activity, sandfly-genic conditions were minimal, resulting in less sandfly abundance. Simsek et al. (2007) had also reported from southern Anatolia, Cukurova region of Turkey, that $\mathrm{S}$ of sandflies was highest (81\%) at altitudinal range between 0-199 m compared to higher altitudinal ranges. Several such investigations carried out elsewhere also support the findings observed in the present study, where the distribution of sandflies showed negative correlation with increase in altitudinal range (Belen \& Alten 2006, Simsek et al. 2007). Belen and Alten (2011) had also reported that sandfly abundance did not show any relationship with increase in altitude. Moreover, the geographical 
and ecological richness of the region provides numerous adult resting and larval sites for sandflies. It seems the altitude is one of several important factors that is necessary to predict the sandfly fauna in a region, but it is not a sufficient factor (Mohammad et al. 2013). Bhunia et al. (2010) reported that the number of kala-azar cases in endemic areas of Bihar decreased with increase in altitudinal range (50-300 m), which was indirectly evident that sandfly abundance diminished with increase in altitude. Further, they also correlated sandfly and sandfly-borne disease distribution with vegetation and found that low density vegetation or nonvegetative areas were found to be a favourable factor for sandfly abundance. Similarly, in the Kani tribe settlements sandfly abundance was high in no canopy-coverage areas.

Expansion of existing tribal settlements has resulted in the conversion of primary forest into secondary forest. Subsequently, Kani tribes altered the environment suitable for cultivation. This was possible, as the settlements receive rainfall throughout the year. Water clog made the soil and organic materials to retain moisture. Thus, a change in the terrain due to human activity changed ecological niches and conditions, favourable for sandfly proliferation. The agricultural activity due to scattering of food grains attracts rodents, which form ideal blood meal source for sandflies. Hence, sandfly abundance was found to be associated with human activities, as highest prevalence of sandflies was obtained in settlements located at the altitudinal ranges between 0-300 m. Cross et al. (1996) and Ghosh et al. (1999) had also observed abundant in areas which were in proximity to vertebrate host and cultivable areas. Further, Azevedo et al. (1996) and Sherlock (1996) had suggested that invasion of human into the forest enhances the risk of spread of sandfly-borne diseases, as zoophagic sandflies get adapted to anthropophagic feeding behaviour.

In the present investigation in tribal settlements located at lower altitudinal range, sandfly $\mathrm{S}$ was high and species diversity and $\mathrm{J}$ were low. Perhaps even distribution of ecological niche due to environmental change suiting to cultivation favoured a particular species to be more abundant, influencing species diversity. Hence, sandfly fauna was rich in this altitudinal range $(0-300 \mathrm{~m})$. Invasion of human in this part of the reserve forest region for domestication and cultivation supported sandfly-genic conditions, favouring sandfly abundance. In view of occurrence of cutaneous leishmaniasis cases among the Kani tribes (VCRC 2012), prevalence of sandflies with multiple hosts feeding pattern, including human (Sathish 2013), there is a risk of transmission of the cutaneous disease among the Kani tribes in the settlements. At this juncture, the investigation on sandfly diversity carried out in the Western Ghats region gains significance.

\section{ACKNOWLEDGEMENTS}

To Dr P Jambulingam, Vector Control Research Centre of Pondicherry, for support to carry out the study in the inaccessible tribal belt, to Directorate of Health Services, Government of Kerala, Directorate of Scheduled Tribe Development Department, Government of Kerala, and Principal Chief Conservator of Forests (Wildlife) and Chief Wildlife Warden,
Kerala, for the facilities provided to carry out the study in the reserve forest region of Western Ghats, and to B Edwin, S Chandrasekaran and N Ramesh, Vector Control Research Centre of Pondicherry, for technical assistance in collecting sandflies in the reserve forest region and in the laboratory.

\section{REFERENCES}

Artemiev MM 1978. Sandflies (Diptera: Psychodidae: Phlebotominae) of Afghanistan, Marzinovoskyi Institute of Medical Parasitology and Tropical Medicine, Moscow, 83 pp.

Azevedo ACR, Vilela ML, Souza NA, Andrade-Coelho CA, Barbosa AF, Firmo ALS, Rangel EF 1996. The sand fly fauna (Diptera: Psychodidae: Phlebotominae) of a focus of cutaneous leishmaniasis in Ilhéus, state of Bahia, Brazil. Mem Inst Oswaldo Cruz 91: 75-79.

Belen A, Alten B 2006. Variation in life table characteristics among populations of Phlebotomus (Phlebotomus) papatasi at different altitude. J Vector Ecol 31: 35-44.

Belen A, Alten B 2011. Seasonal dynamics and altitudinal distributions of sand fly (Diptera: Psychodidae) populations in a cutaneous leishmaniasis endemic area of the Cukurova region of Turkey. J Vector Ecol 36 (Supp1. 1): S87-S94.

Bhunia GS, Kesari S, Jeyaram A, Kumar V, Das P 2010. Influence of topography on the endemicity of kala-azar: a study based on remote sensing and geographical information system. Geospatial Health 4: 155-165.

Cross ER, Newcomb WW, Tucker CJ 1996. Use of weather and remote sensing to predict the geographic and seasonal distribution of Phlebotomus papatasi in Southwest Asia. Am J Trop Med Hyg 54: 530-536.

Dhanda V, Shetty PS, Dhiman RE 1983. Studies on phlebotomine sandflies as vectors of kala-azar in Bihar. Proceedings of IndoUK Workshop on Leishmaniasis, ICMR, New Delhi, 128-137.

Gadgil M 2012. Report of the Western Ghats Ecology Expert Panel. Part I. Available from: from moef.nic.in/downloads/public-information/wg-23052012.pdf.

Ghosh KN, Mukhopadhyy JM, Guzman H, Tesh RB, Munsternmann LE 1999. Interspecific hybridization of genetic variability of Phlebotomus sandflies. Med Vet Entomol 13: 78-88.

Hammer O, Harper DAT, Ryan PD 2001. PAST: Palaeontological statistics software package for education and data analysis. Palaeontol Electron 4: 9 pp.

Jacobson RL, Eisenberger CL, Svobodova M, Baneth G, Sztern J, Carvalho A, Nasereddin M, El Fari M, Shalom U, Volf P, Votypka J, Dedet JP, Pratlong F, Schonian G, Schnur LF, Jaffe CL, Warburg A 2003. Outbreak of cutaneous leishmaniasis in northern Israel. J Infect Dis 188: 1065-1073.

Kalra NL, Bang YH 1988. Manual on entomology in visceral leishmaniasis, World Health Organization, New Delhi, 88 pp.

Killick-Kendrick R 1983. Investigation of phlebotomine sandfliesvector of leishmaniasis. In Proceedings of Indo-UK Workshop on Leishmaniasis, ICMR, New Delhi, p. 72-83.

Killick-Kendrick R 1990. Phlebotomine vectors of leishmaniasis: a review. Med Vet Entomol 4: 1-24.

Kumar V, Kishore K, Palit A, Saran R 1992. A study of species composition, seasonal distribution and habitat of sandflies in the endemic but sprayed area of Patna district, Bihar. Indian J Parasitol 16: 159-160.

Lewis C 2012. Western Ghats. Available from: whc.unesco.org/en/ list/1342. 
Lewis DJ 1978. The phlebotomine sandflies of the Oriental region. Bull Br Mus Nat Hist (Ent) 37: 217-343.

Lewis DJ 1987. The phlebotomine sandflies (Diptera: Psychodidae) from the Oriental Region. Syst Entomol 12: 163-180.

Mohammad A, Mirzaei A, Baghaei A, Alten B, Depaquit J 2013. Sandfly (Diptera: Psychodidae) distribution in the endemic and non-endemic foci of visceral leishmaniasis in north western Iran. $J$ Vector Ecol 38: 97-104.

Parthasarathy N 1999. Tree diversity and distribution in undisturbed and human-impacted sites of tropical wet evergreen forest in southern Western Ghats, India. Biodivers Conserv 8: 1365-1381.

Pascal JP, Ramesh BR, de Franceschi D 2004. Wet evergreen forest types of the southern Western Ghats, India. Trop Ecol 45: 281-292.

Ranjan A, Sur D, Singh VP, Siddique NA, Manna B, Lal CS, Sinha PK, Kishore K, Bhattacharya SK 2005. Risk factors for Indian kala-azar. Am J Trop Med Hyg 73: 74-78.

Sabu TK, Vineesh PJ, Vinod KV 2008. Diversity of forest litter-inhabiting ants along elevations in the Wayanad region of the Western Ghats. J Insect Sci 8: 1-14.

Sathish S 2013. Studies on the natural hosts of sandflies in tribal settlements of the Western Ghats, Thiruvananthapuram, Kerala, a new focus of cutaneous leishmaniasis, MSc Thesis, Pondicherry University, Pondicherry, $68 \mathrm{pp}$.

Sherlock IA 1996. Ecological interactions of visceral leishmaniasis in the state of Bahia, Brazil. Mem Inst Oswaldo Cruz 91: 671-683.

Simi SM, Anish TS, Jyothi R, Vijayakumar K, Philip RR, Paul N 2010. Searching for cutaneous leishmaniasis in tribals from Kerala, India. J Glob Infect Dis 2: 95-100.

Simsek FM, Alten B, Caglar SS, Ozbel Y, Aytekin AM, Kaynas S, Belen A, Kasap OE, Yaman M, Rastgeldi S 2007. Distribution and altitudinal structuring of phlebotomine sand flies (Diptera: Psychodidae) in southern Anatolia, Turkey: their relation to human cutaneous leishmaniasis. J Vector Ecol 32: 269-279.

Srinivasan R, Jambulingam P, Kumar NP 2014. Report of Sergentomyia (Neophlebotomus) monticola, a new sandfly species (Diptera: Psychodidae) from Western Ghats, Thiruvananthapuram district, Kerala, India. Acta Trop 137: 74-79.

Srinivasan R, Jambulingam P, Vanamail P 2013. Sandfly (Diptera: Psychodidae) abundance in relation to environmental factors in parts of coastal plains of southern India. J Med Entomol 50: 758-763.

VCRC - Vector Control Research Centre 2012. Annual report, Vector Control Research Centre/Indian Council of Medical Research, Pondicherry, $63 \mathrm{pp}$. 